BMJ Paediatrics Open

\title{
Effect of bariatric surgery before pregnancy on the vascular function in the offspring: protocol of a cross- sectional follow-up study
}

Karolien Van De Maele, ${ }^{\oplus 1,2}$ Inge Gies, ${ }^{1}$ Roland Devlieger ${ }^{2,3}$

To cite: Van De Maele K, Gies I, Devlieger R. Effect of bariatric surgery before pregnancy on the vascular function in the offspring: protocol of a cross-sectional follow-up study. BMJ Paediatrics Open 2019;3:e000405. doi:10.1136/ bmjpo-2018-000405

Received 5 November 2018 Revised 28 December 2018 Accepted 4 January 2019

Check for updates

\section{(C) Author(s) (or their} employer(s)) 2019. Re-use permitted under CC BY-NC. No commercial re-use. See rights and permissions. Published by BMJ.

${ }^{1}$ Department of Pediatrics, Division of Pediatric Endocrinology, Universitair Ziekenhuis Brussel, Brussels, Belgium

${ }^{2}$ Research Unit Organ Systems, Department of Development and Regeneration, Katholieke Universiteit Leuven Groep Biomedische Wetenschappen, Leuven, Belgium

${ }^{3}$ Department of Obstetrics and Gynecology, Universitaire Ziekenhuizen Leuven, Leuven, Belgium

\section{Correspondence to}

Karolien Van De Maele; karolien. vandemaele@uzbrussel.be

\section{ABSTRACT}

Background The offspring of obese pregnant women are at risk for adverse metabolic, inflammatory and cardiovascular programming. Comprehensive long-term data are lacking on the contribution of changes in maternal weight after bariatric surgery before pregnancy compared with lifestyle interventions during pregnancy on the cardiovascular programming of the offspring.

Methods EFFECTOR is designed as a cross-sectional cohort follow-up study targeting the children of different groups of women who were previously studied during their pregnancy. Four subgroups of children are identified, based on maternal weight characteristics during pregnancy: normal weight women, obese women without any intervention and obese women who underwent a lifestyle intervention during or bariatric surgery before pregnancy. Data collection is performed as a single study visit at home. Data on the sociodemographic situation, food habits and psychomotor development are obtained through questionnaires. During the home visit, extensive anthropometric and vascular assessment is performed. Information on body composition is provided by assessment of body weight and height, bioelectrical impedance analysis, skinfold measurements and ultrasound. Endothelial function is measured by noninvasive peripheral arterial tonometry (EndoPAT 2000). Biomarkers performed in blood and urinalysis conclude the data collection process.

Trial registration number NCT02992106 (Pre-results).

\section{INTRODUCTION}

According to WHO, tackling childhood obesity is one of the major global public health challenges of this century. ${ }^{1}$ Because of a consequently rising incidence of associated diseases, for example, cardiovascular diseases and diabetes, overweight and obesity are seen to be an origin of a continuously intergenerational challenge in the healthcare of future generations.

The research field on maternal obesity is of broad and current interest since there are known adverse outcomes for the offspring both in short and long term. There is an increased risk of large for gestational age or macrosomia, delivery by caesarean section, admission to a neonatal care unit and stillbirth. ${ }^{23}$ Several hypotheses have been formulated trying to identify the in utero origin of long-term adverse metabolic effects on the offspring, including a tendency to insulin resistance, adverse body composition and lipid profile and chronic state of low-grade inflammation. $^{4-9}$

In order to influence these in utero programming processes, the preconception period and early pregnancy are considered as a window of opportunity for healthcare providers. Consensus on the long-term effects of a lifestyle intervention during pregnancy in the offspring is conflicting since most studies use a different methodology making it difficult to draw unambiguous conclusions. ${ }^{10}$ Scarce data might point in the direction of less macrosomia and less obesity at childhood age. $^{3} 1112$ Furthermore, bariatric surgery is widely used when the desired weight loss cannot be obtained through a lifestyle intervention. The current evidence indicates favourable neonatal and long-term outcomes with less macrosomia and large for gestational age, less childhood obesity, favourable lipid profile and less chronic inflammation. ${ }^{13-15}$ Nevertheless, further research is needed to confirm these observed trends.

The cardiovascular effects on the offspring are often mentioned in the same sentence as the adverse metabolic effects but this research area has been studied significantly less. Endothelial cell dysfunction is the preliminary state of atherosclerosis that offers a window of opportunity for a healthcare intervention since the process is still reversible. ${ }^{16}$ Different hypotheses identify a probable fetal origin of the condition, programming the offspring of obese pregnant women for the early development of cardiovascular disease through altered fetal haemodynamics 
and/or increased expression of vascular inflammation markers. ${ }^{5} 917$

The EFFECTOR study is designed as a cross-sectional cohort follow-up study in the offspring of mothers followed in previous studies. ${ }^{11}{ }^{18-23}$ The main outcome is the endothelial function of the offspring measured by non-invasive peripheral arterial tonometry (EndoPAT 2000). The overall objective is to compare the endothelial function of the offspring of mothers suffering from obesity; after they underwent bariatric surgery before pregnancy or a lifestyle intervention during pregnancy.

\section{METHODS AND ANALYSIS}

\section{Study outcomes}

The primary aim of the study is to compare the endothelial function (measured by peripheral arterial tonometry) in the offspring of mothers who underwent bariatric surgery before pregnancy to the endothelial function in the offspring of mothers with obesity during pregnancy.

Our secondary outcome consists of an assessment of body composition, metabolic and inflammatory profile in the offspring after bariatric surgery compared with the other subgroups.

\section{Study design}

The study is designed as a cross-sectional cohort study and the subjects are children of women that were recruited previously in different studies and have a maximum age of 11 years at the start of our study. The children are assigned to a specific subgroup based on the characteristics of their mother, but all subgroups undergo the same prospective data collection procedure. There is no randomisation or blinding procedure.

\section{Patient and public involvement}

Patients were not directly involved in the design of the study.

\section{Study population and recruitment}

The EFFECTOR study population will consist of children whose mothers were recruited in previous Flemish studies, supervised by the Ethical Committee of the University Hospital of Leuven. All of these mothers were well informed about possible follow-up studies at the time of the original study. For reasons of clarification, the children are arbitrarily assigned to a subgroup according to the characteristics of the original maternal cohort, identified as can be seen in table 1 .

The mothers will be contacted by letter or email, including an information brochure. Afterwards, they will be contacted by phone by an investigator to inform them thoroughly and answer all their questions. The inclusion process will start with the eldest children, going gradually down to the youngest ones.

\section{Power calculation and statistics}

The main primary outcome for the endothelial cell function is the Reactive Hyperaemia Index (RHI) measured by the EndoPAT device: a continuous variable, possibly not normally distributed. The power calculation is based on the existing literature and the subgroups where we expect the largest difference. ${ }^{9}{ }^{24}$ Assuming a mean of 1.6 in the offspring of obese mothers without intervention compared with 1.9 in the normal weight group, with an $\mathrm{SD}$ of 0.05 , assuming a participation rate of one in three $(35 \%)$, that is, 45 children of obese mothers without intervention and 58 children in the control group, we have a power of 0.82 to demonstrate a statistically significant difference between the two groups (two-sided significance level $<0.05$, Mann-Whitney $\mathrm{U}$ test). If the actual difference in RHI would be larger, for example, 0.5 (1.4 vs 1.9 ), then the power of the test increases to 0.99 .

A participation rate of $35 \%$ is feasible, based on reported response rates in literature and a high response rate (almost 50\%) in a follow-up study that is actually

Table 1 Overview of original maternal cohorts and characteristics during pregnancy

\begin{tabular}{|c|c|c|c|}
\hline $\begin{array}{l}\text { Maternal pregnancy } \\
\text { characteristics }\end{array}$ & Original cohort & $\begin{array}{l}\text { Women in } \\
\text { cohort }\end{array}$ & Recruitment \\
\hline \multirow[t]{2}{*}{$\begin{array}{l}\text { Bariatric surgery before } \\
\text { pregnancy }\end{array}$} & $\begin{array}{l}\text { Pregnancy after bariatric surgery } \\
\text { cohort }^{20}\end{array}$ & $\mathrm{~N}=49$ & $\begin{array}{l}\text { Five Flemish hospitals } \\
\text { Inclusion before } 15 \text { weeks of gestation }\end{array}$ \\
\hline & $\begin{array}{l}\text { Bariatric surgery registration in } \\
\text { women of reproductive age cohort }\end{array}$ & $\begin{array}{l}\text { Aim } 200 \text { (still } \\
\text { recruiting) }\end{array}$ & $\begin{array}{l}\text { Eight Flemish hospitals } \\
\text { Inclusion before bariatric surgery }\end{array}$ \\
\hline Normal weight & $\begin{array}{l}\text { Bogaerts et al } \\
18\end{array}$ & $N=156$ & Three regional Belgian hospitals \\
\hline \multirow[t]{2}{*}{$\begin{array}{l}\text { Overweight or obesity during } \\
\text { pregnancy }\end{array}$} & $\underset{21}{\text { Guelinckx et al }}$ & $\mathrm{N}=65$ & University Hospital of Leuven \\
\hline & $\begin{array}{l}\text { Bogaerts et al } \\
18\end{array}$ & $\mathrm{~N}=63$ & Three regional Belgian hospitals \\
\hline \multirow{2}{*}{$\begin{array}{l}\text { Overweight or obesity with } \\
\text { lifestyle intervention during } \\
\text { pregnancy }\end{array}$} & DALI cohort ${ }^{2329}$ & $\mathrm{~N}=100$ & $\begin{array}{l}\text { University Hospital of Leuven, part of } \\
\text { European randomised controlled trial }\end{array}$ \\
\hline & $\underset{21}{\text { Guelinckx et al }}$ & $N=130$ & University Hospital of Leuven \\
\hline
\end{tabular}


ongoing on the children of one of the original cohorts. With a participation rate of $35 \%$, we subsequently have 80 children of obese mothers with lifestyle intervention and 87 children of mothers after bariatric surgery, so in total 270 children. Comparing the other subgroups will be exploratory, no formal hypotheses are available in the literature.

The statistical analysis will be performed by using an intention-to-treat principle. The statistical software package IBM SPSS V.24 will be used for the analyses. Descriptive statistics will be used for the description of the study population at baseline. RHI will be assessed as continuous variable. Linear regression will be used if the Gauss-Markov assumptions can be met. Otherwise, quantile regression will be used. The association between continuous explanatory variables and the outcome RHI will be assessed using splines or loess smoothers. Explanatory variables are at least the four groups (obese no intervention, obese lifestyle intervention, bariatric and control), children's age, children's body mass index (BMI), children's metabolic profile, children's eating behaviour, sociodemographic characteristics.

\section{Data collection process}

Secondary data analysis

After obtaining a written informed consent, this section of data collection will ensue by collecting available data from the previous studies. The collection of these data took place in a prospective manner at the time of the previous studies. The collection of these data will give us the opportunity to set a point of origin for all the children that will participate in our study.

The secondary data consist of the following data: maternal prepregnancy weight, pregnancy weight gain, pregnancy and birth outcomes such as pregnancy duration and birth weight, relevant medical (and obstetric) history (previous bariatric surgery, identification of any pregnancy lifestyle intervention, pre-eclampsia); biochemical data (white cell count, glucose metabolism screening and $\mathrm{C}$ reactive protein (CRP) at time of delivery).

\section{Prospective data collection}

Data will be obtained by performing a single home visit for approximately $90 \mathrm{~min}$ to gather additional data independently from the age of the child at that time (depends on the year when the mother was included in the previous study). An overview of the study intervention can be seen in figure 1. This intervention is identical for all the subgroups of the cohort and will contain the following parts:

\section{Peripheral arterial tonometry}

Pulse wave amplitude will be measured by using a finger plethysmograph (peripheral arterial tonometry) by using the EndoPAT device from Itamar Medical. Briefly explained, both index fingers of the patient are placed in the pneumatic probes. First, the device performs 5 min of baseline measurement and thereafter a blood pressure cuff occludes the arterial flow of the arm for $5 \mathrm{~min}$. After a rapid deflation of the cuff, a reactive hyperaemia takes place, which is a measure for the arterial endothelial function. There is a concomitant software package. Children on growth hormone treatment will be excluded for the test with the EndoPAT, since this drug influences the test result. ${ }^{25}$ If there is an infection ongoing, the examination will be postponed for 2 weeks. Since taking a blood sample can influence the test results as well, the blood sample will be done after the test with the EndoPAT device. $^{25}$

\section{Anthropometric data}

The anthropometric data will consist of weight and height, four site skinfold measurement, neck, waist and hip circumference, body composition by bioelectrical impedance analysis (BIA), ultrasound and blood pressure. Standing height will be measured using a portable stadiometer with a movable headboard and vertical backboard (Seca 217, SECA, Hamburg, Germany). The body weight and total body fat percentage will be assessed by using a BIA (Tanita MC-780U). BMI will be calculated from measured weight and height and expressed as SDS according to the Flemish growth charts. Pubertal development will be assessed according to Tanner stages. Skinfold measurements will be performed at biceps, triceps, subscapular and suprailiac site with a Harpenden skinfold caliper (Baty international, RH15 9LB England). A portable ultrasound device with a linear probe $7.5 \mathrm{MHz}$ (Mindray, Diagnostic Ultrasound System, model M 7) will be used to measure the abdominal subcutaneous fat thickness at the four sites of the skinfold measurements. The girths of neck, abdomen and hip will be measured with a flexible Lufkin steel anthropometric tape (Lufkin W606PM). Blood pressure will be measured using a Mindray VS-900. After performing the measurements with the EndoPAT device, Harpenden caliper and ultrasound, the children will be asked to fill out a Faces Pain Scale, validated for children aged 4-16 years old and obtained for use from the International Association for the Study of Pain. ${ }^{26}$ The International Standards for Anthropometric Assessment set by the International Society for the Advancement of Kinanthropometry and standard operation procedures will be taken into account to ensure data quality. ${ }^{27}$

\section{Biochemical data}

A blood sample will be taken by a venipuncture after an overnight of fastening. The serum samples will be stored in appropriate manner during transportation to be processed in a centralised laboratory. All laboratory analyses will be performed by using the laboratory techniques available in the University Hospital of Brussels. Following biochemical parameters will be determined: glucose, insulin, total cholesterol, Low Density Lipoprotein cholesterol (LDL), High Density Lipoprotein cholesterol(HDL), triglycerides, uric acid, IGF-1, adiponectin, 


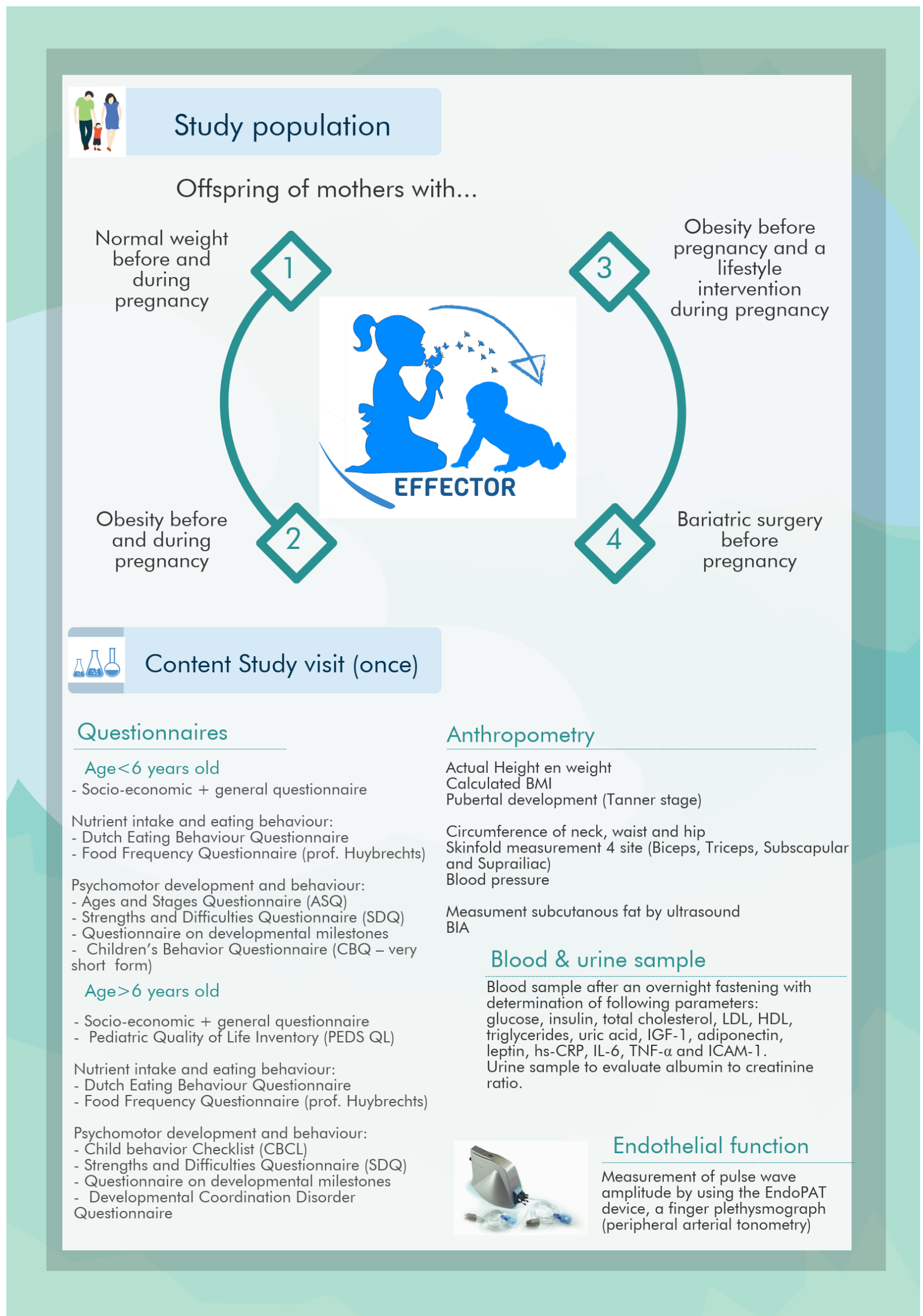

Figure 1 This figure provides a graphical overview of the data collection process as it was designed for the EFFECTOR study. BIA, bioelectrical impedance analysis; BMI, body mass index; hs-CRP, high-sensitivity C reactive protein; TNF, tumour necrosis factor alpha. 
Table 2 Overview of used questionnaires in the data collection process with the purpose

\begin{tabular}{|c|c|c|}
\hline Questionnaire & Who? & Purpose \\
\hline Socodemographic (designed for the study) & All & $\begin{array}{l}\text { Obtain family composition, education level and employment status } \\
\text { of the parents, medical history and school level of the child. }\end{array}$ \\
\hline Food Frequency ${ }^{31-33}$ & All & $\begin{array}{l}\text { Evaluation of food intake based on the frequency and portion size } \\
\text { of } 47 \text { food items. }\end{array}$ \\
\hline $\begin{array}{l}\text { Developmental milestones (designed for the } \\
\text { study-short 8-item) }\end{array}$ & All & $\begin{array}{l}\text { Obtain child's age at achieving the most obvious developmental } \\
\text { milestones. }\end{array}$ \\
\hline Strengths and Difficulties Questionnaire ${ }^{34-36}$ & All & $\begin{array}{l}\text { Screening tool for mental health problems and common forms of } \\
\text { psychopathology. }\end{array}$ \\
\hline $\begin{array}{l}\text { Developmental Coordination Disorder } \\
\text { Questionnaire }^{37}\end{array}$ & $\geq 5$ years & $\begin{array}{l}\text { Detect Developmental Coordination Disorder (DCD) in children } \\
\text { aged } 5-15 \text { years. }\end{array}$ \\
\hline Ages and Stages Questionnaire ${ }^{38}$ & $\leq 5$ years & Screening tool for neurodevelopmental disorders. \\
\hline Child Behaviour Checklist & $\geq 6$ years & Additional differentiating (eventual) psychopathology. \\
\hline
\end{tabular}

leptin, high-sensitivity CRP, IL-6, tumour necrosis factor alpha and ICAM-1.

A urine sample will be taken to evaluate the albumin to creatinine ratio. This urine sample will be a morning urine portion and we will ask the participants not to engage in physical activity in the preceding 48 hours. This method has been validated by Bartz et al and is considered an early marker of endothelial dysfunction. ${ }^{28}$

\section{Questionnaires data}

Prior to the home visit, the parents will receive a web-based link to fill in the questionnaires. If they do not have a computer or internet available at their home, the investigator will offer them the chance to fill in the questionnaires on a laptop or tablet during the home visit. In order to avoid bias, the investigator will not provide them with any additional information. An overview of the used questionnaires is provided in table 2 .

\section{ETHICS AND DISSEMINATION}

Consent

The study will be conducted only after obtaining a prior informed consent of the legal representatives of the children and obtaining an assent of the children according to their age and maturity. The legal representatives of the children will sign an informed consent form and the assent of the children will be noted in the corresponding file. The informed consent form and the assent are reviewed and approved by the Ethics Committee prior to the start of recruitment.

The collection, processing and disclosure of personal data, such as patient health and medical information, is subject to compliance with applicable personal data protection and the processing of personal data (Directive
95/46/EC and Belgian law of 8 December 1992 on the Protection of the Privacy in relation to the Processing of Personal Data). The data will be coded. The research team will protect the data from disclosure outside the research according to the terms of the research protocol and the informed consent document. The subject's name or other identifiers will be stored separately from their research data and replaced with a unique code to create a new identity for the subject.

\section{Safety}

The venipuncture for the blood sample can cause transient pain, a syncope, a haematoma or a local skin infection. The peripheral arterial tonometry can cause a tingling feeling in the occluded arm that will disappear after deflation of the cuff. All of these aforementioned adverse events are not considered as serious adverse events. If they occur, however, they will be reported according to the rules of Good Clinical Practice in the case report form.

\section{Publication policy}

All publication rights of unprocessed and processed data belong to the investigators. The data are coded and treated confidential. Participant anonymity is guaranteed during the publication of the study results.

Contributors KVDM, IG and RD contributed to the design of the study. KVDM wrote the manuscript. IG and RD did a critical revision of the manuscript. The funding organisations performed a peer-review of the protocol.

Funding The research activities of KVDM are funded by a doctoral research grant from the Belgian Society for Pediatric Endocrinology and Diabetology (BESPEED) and additional research funding from Wetenschappelijk Fonds Willy Gepts of the UZ Brussel.

Competing interests None declared. 
Patient consent Not required.

Ethics approval The study obtained approval from the central Ethics Committee UZ Brussels, which provides final ethical approval (22 February 2017), and the local Ethics Committee UZ Leuven/KU Leuven. The Faces Pain Scale was added as an amendment, which was approved by the Ethics Committee (15 January 2018). Changes to the study protocol will be submitted to the Ethics Committee and will not be performed before obtaining an approval.

Provenance and peer review Not commissioned; externally peer reviewed.

Open access This is an open access article distributed in accordance with the Creative Commons Attribution Non Commercial (CC BY-NC 4.0) license, which permits others to distribute, remix, adapt, build upon this work non-commercially, and license their derivative works on different terms, provided the original work is properly cited, appropriate credit is given, any changes made indicated, and the use is non-commercial. See: http://creativecommons.org/licenses/by-nc/4.0/.

\section{REFERENCES}

1. World Health Organisation. Obesity and Overweigt. Fact Sheet $\mathrm{N}^{\circ}$ 311. 2016 http://www.who.int/mediacentre/factsheets/fs311/en/.

2. Devlieger R, Benhalima K, Damm P, et al. Maternal obesity in Europe: where do we stand and how to move forward?: A scientific paper commissioned by the European Board and College of Obstetrics and Gynaecology (EBCOG). Eur J Obstet Gynecol Reprod Biol 2016;201:203-8.

3. Tanvig M. Offspring body size and metabolic profile - effects of lifestyle intervention in obese pregnant women. Dan Med J 2014;61:B4893.

4. Wankhade UD, Thakali KM, Shankar K. Persistent influence of maternal obesity on offspring health: Mechanisms from animal models and clinical studies. Mol Cell Endocrinol 2016;435:7-19.

5. O'Reilly JR, Reynolds RM. The risk of maternal obesity to the longterm health of the offspring. Clin Endocrinol 2013;78:9-16.

6. Galjaard S, Devlieger R, Van Assche FA. Fetal growth and developmental programming. J Perinat Med 2013;41:101-5.

7. Santangeli L, Sattar N, Huda SS. Impact of maternal obesity on perinatal and childhood outcomes. Best Pract Res Clin Obstet Gynaecol 2015;29:438-48.

8. Godfrey KM, Reynolds RM, Prescott SL, et al. Influence of maternal obesity on the long-term health of offspring. Lancet Diabetes Endocrinol 2017;5:53-64.

9. Van De Maele K, Devlieger R, Gies I. In utero programming and early detection of cardiovascular disease in the offspring of mothers with obesity. Atherosclerosis 2018;275:182-95.

10. Flynn AC, Dalrymple K, Barr S, et al. Dietary interventions in overweight and obese pregnant women: a systematic review of the content, delivery, and outcomes of randomized controlled trials. Nutr Rev 2016;74:312-28.

11. Bogaerts A, Ameye L, Martens E, et al. Weight loss in obese pregnant women and risk for adverse perinatal outcomes. Obstet Gynecol 2015;125:566-75.

12. Muktabhant $B$, Lawrie TA, Lumbiganon $P$, et al. or both, for preventing excessive weight gain in pregnancy. Cochrane Database Syst Rev 2015;6:CD007145.

13. Smith J, Cianflone K, Biron S, et al. Effects of maternal surgical weight loss in mothers on intergenerational transmission of obesity. $J$ Clin Endocrinol Metab 2009;94:4275-83.

14. Johansson K, Cnattingius S, Näslund I, et al. Outcomes of pregnancy after bariatric surgery. N Engl J Med 2015;372:814-24.

15. Kjær MM, Lauenborg J, Breum BM, et al. The risk of adverse pregnancy outcome after bariatric surgery: a nationwide registerbased matched cohort study. Am J Obstet Gynecol 2013;208:464. e1-464.e5.

16. Bruyndonckx L, Hoymans VY, Van Craenenbroeck AH, et al. Assessment of endothelial dysfunction in childhood obesity and clinical use. Oxid Med Cell Longev 2013;2013:1-19.

17. Roberts VH, Frias AE, Grove KL. Impact of maternal obesity on fetal programming of cardiovascular disease. Physiology 2015;30:224-31.

18. Bogaerts AF, Devlieger R, Nuyts E, et al. Anxiety and depressed mood in obese pregnant women: a prospective controlled cohort study. Obes Facts 2013;6:152-64.
19. Bogaerts AF, Devlieger R, Nuyts E, et al. Effects of lifestyle intervention in obese pregnant women on gestational weight gain and mental health: a randomized controlled trial. Int J Obes 2013;37:814-21.

20. Guelinckx I, Devlieger R, Donceel P, et al. Lifestyle after bariatric surgery: a multicenter, prospective cohort study in pregnant women. Obes Surg 2012;22:1456-64.

21. Guelinckx I, Devlieger R, Mullie P, et al. Effect of lifestyle intervention on dietary habits, physical activity, and gestational weight gain in obese pregnant women: a randomized controlled trial. Am J Clin Nutr 2010;91:373-80.

22. Jans G, Matthys C, Bel S, et al. AURORA: bariatric surgery registration in women of reproductive age - a multicenter prospective cohort study. BMC Pregnancy Childbirth 2016;16:195.

23. Jelsma JG, van Poppel MN, Galjaard S, et al. DALI: Vitamin D and lifestyle intervention for gestational diabetes mellitus (GDM) prevention: an European multicentre, randomised trial - study protocol. BMC Pregnancy Childbirth 2013;13:142.

24. Pareyn A, Allegaert K, Asscherickx W, et al. Impaired endothelial function in female adolescents with type 1 diabetes measured by peripheral artery tonometry. Eur J Pediatr 2013;172:1017-22.

25. Bruyndonckx L, Radtke T, Eser P, et al. Methodological considerations and practical recommendations for the application of peripheral arterial tonometry in children and adolescents. Int $J$ Cardiol 2013;168:3183-90.

26. Hicks CL, von Baeyer CL, Spafford PA, et al. The Faces Pain ScaleRevised: toward a common metric in pediatric pain measurement. Pain 2001;93:173-83.

27. Stewart A, Marfell-Jones M. International standards for anthropometric assessment. International Society for the Advancement of Kinanthropometry 2011.

28. Bartz SK, Caldas MC, Tomsa A, et al. Urine Albumin-to-Creatinine Ratio: A Marker of Early Endothelial Dysfunction in Youth. J Clin Endocrinol Metab 2015;100:3393-9.

29. de Wit L, Jelsma JG, van Poppel MN, et al. Physical activity, depressed mood and pregnancy worries in European obese pregnant women: results from the DALI study. BMC Pregnancy Childbirth 2015;15:158.

30. van Strien T, Oosterveld P. The children's DEBQ for assessment of restrained, emotional, and external eating in 7- to 12-year-old children. Int J Eat Disord 2008;41:72-81.

31. Huybrechts I, De Bacquer D, Matthys C, et al. Validity and reproducibility of a semi-quantitative food-frequency questionnaire for estimating calcium intake in Belgian preschool children. $\mathrm{Br} \mathrm{J}$ Nutr 2006;95:802-16.

32. Huybrechts I, De Backer G, De Bacquer D, et al. Relative validity and reproducibility of a food-frequency questionnaire for estimating food intakes among Flemish preschoolers. Int J Environ Res Public Health 2009;6:382-99.

33. Huybrechts I, Vereecken C, De Bacquer D, et al. Reproducibility and validity of a diet quality index for children assessed using a FFQ. $\mathrm{Br}$ J Nutr 2010;104:135-44

34. Goodman R, Ford T, Simmons $\mathrm{H}$, et al. Using the Strengths and Difficulties Questionnaire (SDQ) to screen for child psychiatric disorders in a community sample. Int Rev Psychiatry 2003;15(12):166-72.

35. Theunissen MH, Vogels AG, de Wolff MS, et al. Characteristics of the strengths and difficulties questionnaire in preschool children. Pediatrics 2013;131:e446-e454.

36. van Widenfelt BM, Goedhart AW, Treffers PD, et al. Dutch version of the Strengths and difficulties Questionnaire (SDQ). Eur Child Adolesc Psychiatry 2003;12:281-9.

37. Wilson BN, Crawford SG, Green D, et al. Psychometric properties of the revised developmental coordination disorder questionnaire. Phys Occup Ther Pediatr 2009;29:182-202.

38. Schonhaut L, Armijo I, Schönstedt M, et al. Validity of the ages and stages questionnaires in term and preterm infants. Pediatrics 2013;131:e1468-e1474

39. Varni JW, Burwinkle TM, Seid M, et al. The PedsQL 4.0 as a pediatric population health measure: feasibility, reliability, and validity. Ambul Pediatr 2003;3:329-41.

40. Rothbart MK, Ahadi SA, Hershey KL, et al. Investigations of temperament at three to seven years: the Children's behavior questionnaire. Child Dev 2001;72:1394-408. 